\title{
Review of: "Ventilator output splitting interface 'ACRA': Description and evaluation in lung simulators and in an experimental ARDS animal model"
}

\author{
Barbara Stankiewicz
}

Potential competing interests: The author(s) declared that no potential competing interests exist.

The study is interesting, and the subject is worth to be developed, in the future. The authors presented a new device enabling ventilation of two patients with one ventilator. It could be helpful in crises situations (lack of ventilators), e.g. in pandemic conditions.

My remarks concerning the study are as follows:

1. Considering results from Table 4, the question of delivery required tidal volume (Vt) to the patient lungs should be more extensively examined, in the future (see (A-C) significant differences in Vt, at PIP of 25 and $\left.15 \mathrm{cmH}_{2} \mathrm{O}\right)$.

2. What was the sample size $(n)$ used for the calculation of $\mathrm{Cl}(95 \%)$ ? The $\mathrm{Cl}$ ranges are wide, e.g. for $\mathrm{PaCO}_{2}, \mathrm{HR}, \mathrm{MAP}$. Is it possible?

3. The role of the bypass circuit between the inspiratory and expiratory line is, in my opinion, controversial, because it could result in cross-contamination. A one-way valve should be part of the circuit to avoid it. If I well understood, the authors of the study did not include such a valve in the bypass circuit. Probably, the use of a one-way valve could cause that the bypass circuit would not fulfil the assumed function. Due, to that I encourage authors to search for other solutions (instead of the bypass circuit) to solve the problem with PEEP and undesirable ventilator responses. 